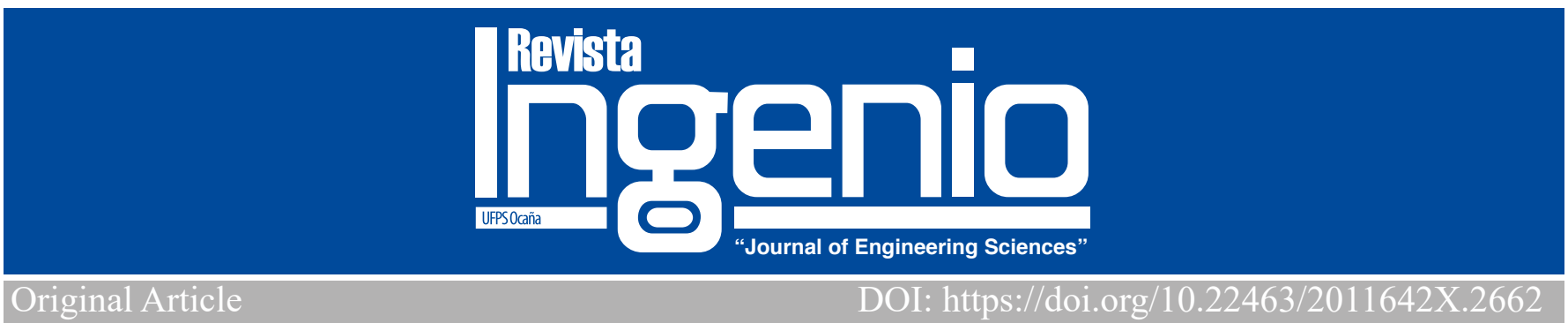

\title{
Determination of stresses in two-way slabs of concrete through the finite difference method
}

Determinación de esfuerzos en losas de hormigón bidireccional mediante el método de diferencias finitas MSc. Carlos Valbson dos Santos-Araújo ${ }^{1}$, MSc. João Paulo Matos-Xavier ${ }^{2}$, MSc. Robson Lopes-Pereira ${ }^{3}$

\footnotetext{
Universidade de Brasilia, Brasilia, Brazil, Orcid: https://orcid.org/0000-0003-2661-6084,Email: car-los.valbson.araujo@gmail.com

Universidade Federal Rural do Semi-Árido, Mossoró, Brazil, Orcid: https://orcid.org/0000-0003-0843-1051, Email: joao-paulo@ufersa.edu.br

Universidade católica de Goiás, Goiânia, Brazil, Orcid: https://orcid.org/0000-0001-8767-1787,Email: robsonlopesprofessor@gmail.com
}

How to cite: C. V. S. Araújo,J. P. M. Xavier \& R. L. Pereira, "Determination of stresses in to-way slabs of concrete through the finite difference method", Revista Ingenio, 18(1), pp. 25-32,2021.

Key words:

From the implementation of analytical solutions for thin rectangular slabs using the Finite Difference Method, the present paper was developed with the purpose of comparing the determined stresses in a concrete plate with those that would be obtained using

Concrete, Elastic method, Finite differences method, Two-way Slabs. the tables originated from the plate theory found in the literature. For this, the Python programming lan-guage was used, taking as a case study, a slab with dimensions of $5 \mathrm{~m}$ long by $3 \mathrm{~m}$ wide and thickness equal to $0.10 \mathrm{~m}$. In the analysis of the stresses, several support conditions were considered, in which the internal stresses and displacements obtained by the Finite Difference Method were compared with the results obtained through the tables proposed in the litera-ture. It was verified that the Finite Difference Method constitutes a good alternative for the resolution of thin solid plates, since the results were similar to the classic solution proposed in the literature. The implemented program allows the visual-ization of the stresses through of spectrums of zone which facilitates the understanding of the distribution of the stresses along the slab, differing slightly from the uniform distribution adopted in the tables consulted.

\section{RESUMEN}

Palabras claves:

Hormigón, Método elástico, Método de diferencias finitas, Losas bidireccionales.

\begin{abstract}
A partir de la implementación de soluciones analíticas para losas rectangulares delgadas utilizando el Método de Diferencias Finitas, el presente artículo tiene como objetivo comparar los esfuerzos determinados sobre una placa de hormigón con los que se encontrarían utilizando tablas originadas a partir de la teoría de las placas de los autores consagrado en la literatura. Para ello, se utilizó el lenguaje de programación Python, tomando como caso de estudio, una losa con dimensiones de $5 \mathrm{~m}$ de largo por $3 \mathrm{~m}$ de ancho y grosor igual a $0.10 \mathrm{~m}$. En el análisis de esfuerzos se consideraron varias condiciones de apoyo y se compararon los esfuerzos y desplazamientos internos encontrados por el Método de Diferencias Finitas con los resultados obtenidos a través de las Tablas propuestas en la literatura. Se encontró que el Método de Diferencias Finitas es una buena alternativa para la resolución de losas delgadas, ya que los resultados fueron similares a la solución clásica propuesta en la literatura. El programa implementado permite visualizar los esfuerzos a través de los espectros de rango que facilitó la comprensión de su distribución a lo largo de la losa, diferenciándose de la distribución uniforme adoptada en las tablas consultadas.
\end{abstract}

\section{Introduction}

With regard to the design of two-way slabs, there are basically two calculation methods: the elastic method and the rupture method. The first is based on the analysis of the behavior of the element under service loads and intact (noncracked) concrete. The second is based on the mechanisms of breaking the slabs.

There are several processes for determining the stresses, among which we can highlight: finite difference, finite elements, equivalent grid and use of series to represent the load value in each coordinate of the plane $(p(x, y))$.

Thus, the objective of this work is to present a comparative study between the stresses deter-mined by the finite difference method and the tables proposed by [1]. For this, an implementation of an algorithm in Python programming language, analyzing a slab with different boundary conditions, was made. 


\section{Calculation methods}

\subsection{Elastic method}

The elastic method (classic) can also be called the Kirchhoff-Love theory of plates. This method is based on the equilibrium equations of an infinitesimal plate element and on the compatibility relationships of the deformations of that element [2-3].

According to item 14.7.3 of Brazilian code for design of concrete structures, NBR 6118 [4], methods based on the theory of elasticity can be used in plate structures, with Poisson's ratio $v$ equal to 0.2 , as long as the conditions dealing with linear analysis, stiffness values, redistributing moments, and ductility are met.

In order to use this method, it is necessary to admit some hypotheses, that is: homogeneous, elastic, isotropic material, physically linear and small displacements. It is also admitted that the section remains flat after deformation and the elements representation can be done through its average plane.

In order to facilitate the use of boundary conditions in solving the stress determination prob-lem, most of the time, other considerations are made, such as: the action of the plates on the contour beams occurs only by means of vertical forces, with no transmission of torsion or moments to the beams; the actions of the plates on the contour beams are uniformly distributed, and there is no load transmission directly to the columns; the contour beams cannot be displaced in the vertical direction; and the rotation of the plates in the contour is free (simple support) or totally prevented (embedded).

\subsection{Fundamental equation (thin plates)}

The fundamental differential equation of the thin plates (obtained by equilibrium and compatibility of displacements of an infinitesimal element, relating bending moments with curvature), subjected to a load $p(x, y)$, is presented below:

$$
\frac{d^{4} w}{d x^{4}}+2 \frac{d^{4} w}{d x^{2} d y^{2}}+\frac{d^{4} w}{d y^{4}}=\frac{p}{D}
$$

where:

$W$ - Vertical displacement;

$X, Y$-Coordinates of a generic point on the plate;

$P$ - Intensity of the active load;

$D=\frac{E h^{3}}{12\left(1-v^{2}\right)}-$ Rigidity to plate flexion;

$h$-Plate thickness;

$v$ - Poisson's ratio;

$E$ - Longitudinal elastic modulus of concrete.
Solving the fundamental equation (1), we obtain the expression for the elastic surface $w=(x, y)$, and with its derivatives, the moments $m_{x}$ and $m_{y}$ in directions $x$ and $y$, are pre-sented in respectively equations:

$$
\begin{aligned}
& \frac{m_{x}}{D}=\frac{d^{2} w}{d x^{2}}+v \frac{d^{2} w}{d y^{2}} \\
& \frac{m_{y}}{D}=\frac{d^{2} w}{d y^{2}}+v \frac{d^{2} w}{d x^{2}}
\end{aligned}
$$

The fundamental equation was obtained for moments acting per unit of length, that is, if acting a total moment $M x$ (adopts as $M x$ the moment that must be resisted in the direction $x$ ) on the plate, of width $l y$, the moment $l y$ in a unit width (Figure 1) is shown below:

$$
m_{x}=\frac{M_{x}}{l_{y}}
$$

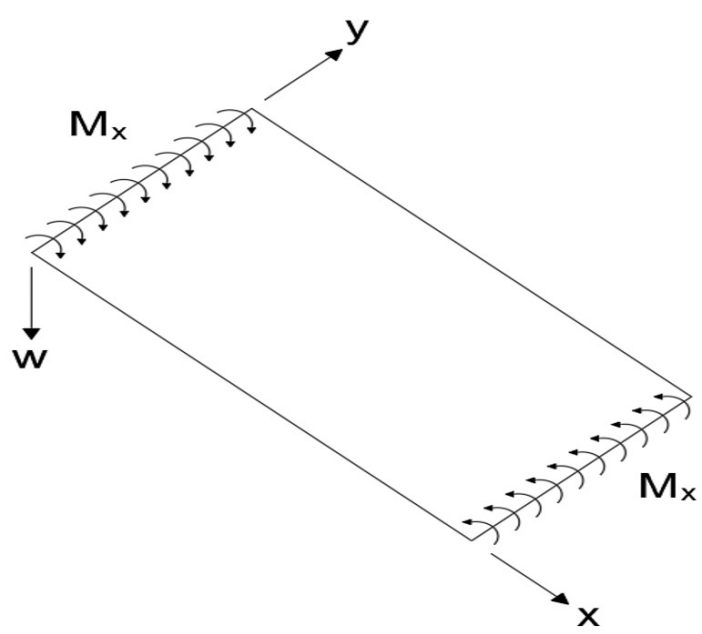

Figure 1. Moment $m_{x}$ per unit length acting on the plate. Source [2].

\subsection{Finite Difference Method}

The Finite Difference Method is a method of solving differential equations that is based on the approximation of derivatives by finite differences [5-6]. In this item, the approach of this method performed by [7] is presented.

So, let $\Delta x>0$ and consider the following Taylor series of a function around a point $x_{0}$, respectively to the right and left:

$$
\begin{aligned}
& u\left(x_{0}+\Delta x\right)= \\
& u\left(x_{0}\right)+\frac{d u}{d x}\left(x_{0}\right) \Delta x+\frac{1}{2 !} \frac{d^{2} u}{d x^{2}}\left(x_{0}\right) \Delta x^{2}+\ldots \\
& u\left(x_{0}-\Delta x\right)= \\
& u\left(x_{0}\right)-\frac{d u}{d x}\left(x_{0}\right) \Delta x+\frac{1}{2 !} \frac{d^{2} u}{d x^{2}}\left(x_{0}\right) \Delta x^{2}-\ldots
\end{aligned}
$$




\section{Determination of stresses in two-way slabs of concrete through the finite difference method}

Denoting $\Delta x^{n}=(\Delta x)^{n}$ and isolating the first de-rivative, we have:

$$
\begin{aligned}
& \frac{d u}{d x}\left(x_{0}\right)= \\
& \frac{u\left(x_{0}+\Delta x\right)-u\left(x_{0}\right)}{\Delta x}-\frac{1}{2 !} \frac{d^{2} u}{d x^{2}}\left(x_{0}\right) \Delta x-\ldots \\
& \frac{d u}{d x}\left(x_{0}\right)= \\
& \frac{u\left(x_{0}\right)-u\left(x_{0}-\Delta x\right)}{\Delta x}+\frac{1}{2 !} \frac{d^{2} u}{d x^{2}}\left(x_{0}\right) \Delta x-\ldots
\end{aligned}
$$

Immediately two possible approximations are obtained for the first derivative of $u$ in $x_{0}$, as shown below:

$$
\begin{aligned}
& \frac{d u}{d x}\left(x_{0}\right) \approx \frac{u\left(x_{0}+\Delta x\right)-u\left(x_{0}\right)}{\Delta x} \\
& \frac{d u}{d x}\left(x_{0}\right) \approx \frac{u\left(x_{0}\right)-u\left(x_{0}-\Delta x\right)}{\Delta x}
\end{aligned}
$$

Equation (9) is called a progressive finite difference and equation (10) is called Finite Difference Regression.

\section{Calculation of thin slabs}

According to [2-8], the calculation of slabs by finite differences consists of the numerical integration of the differential equation, which is re-placed by another of finite differences. Here, the plate is divided into a mesh that adapts to its outline, and the derivatives are replaced by approximate expressions, determined through the use of convenient interpolation polynomials.

The derivatives of the polynomial are consid-ered approximately equal to those of the unknown function, whose partial derivatives are intended to be replaced by finite differences, such as:

$$
\frac{d y}{d x} \cong \frac{\Delta y}{\Delta x} \cong \frac{y_{2}-y_{1}}{x_{2}-x_{1}}
$$

Also, according to [9] apud [2], these expres-sions are applied to several points, allowing the solution of the problem to be made, generally, through a system of linear equations. In order to facilitate the understanding of the use of the Finite Difference Method in solving thin plate dif-ferential equations, the approach performed by [10] is presented. As shown in Figure 2, one can observe the nodal points that form the finite dif-ference mesh. Thus, it is expected that the greater the number of points, the better the approximation.

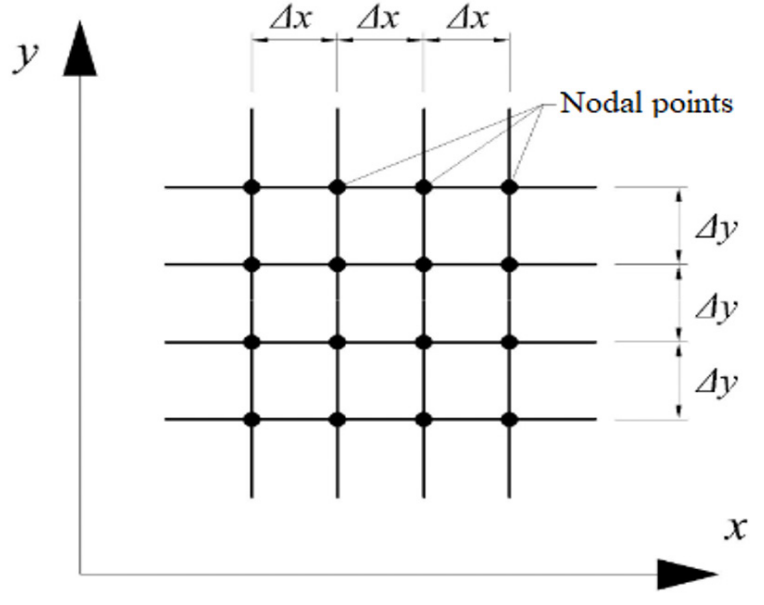

Figure 2. Finite difference mesh. Source [10].

From equation (1), the finite difference equation can be obtained:

$$
\sum_{i=1}^{13} \alpha_{i} w_{i}=\frac{q \Delta x^{4}}{D}
$$

Figure 3 shows the numbering of the nodes corresponding to the displacements $\left(W_{i}\right)$ of equation (12).

The $a_{i}$ coefficients are presented in the following set of equations:

$$
\begin{aligned}
& \alpha_{1}=6+6\left(\frac{\Delta x}{\Delta y}\right)^{4}+8\left(\frac{\Delta x}{\Delta y}\right)^{2} \\
& \alpha_{2}=\alpha_{4}=-4\left[1+\left(\frac{\Delta x}{\Delta y}\right)^{2}\right] \\
& \alpha_{3}=\alpha_{5}=-4\left(\frac{\Delta x}{\Delta y}\right)^{2}\left[1+\left(\frac{\Delta x}{\Delta y}\right)^{2}\right] \\
& \alpha_{6}=\alpha_{7}=\alpha_{8}=\alpha_{9}=-2\left(\frac{\Delta x}{\Delta y}\right)^{2} \\
& \alpha_{10}=\alpha_{12}=\left(\frac{\Delta x}{\Delta y}\right)^{4} \\
& \alpha_{11}=\alpha_{13}=1
\end{aligned}
$$




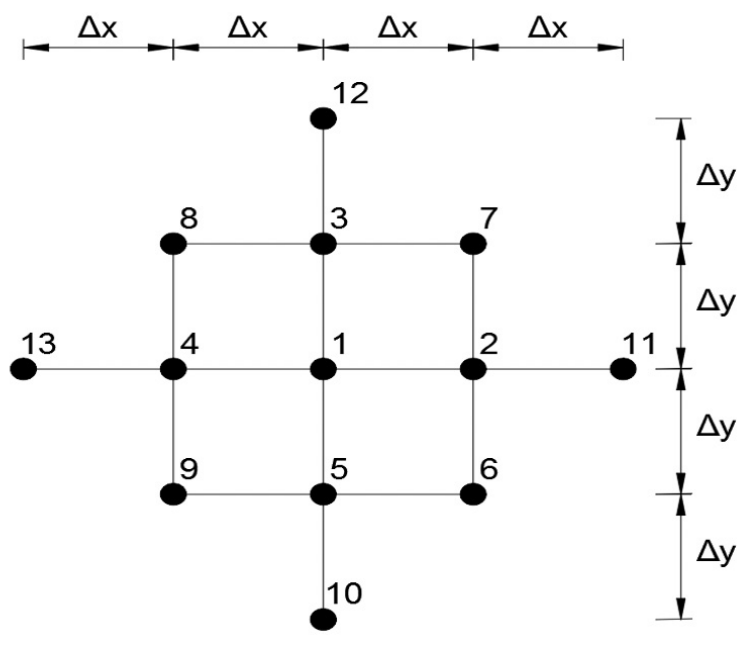

Figure 3. Local numbering for the determination of displacement coefficients. Source [10].

Using the coefficients presented in the set of equations (13) and in the sum presented in equation (12), and referencing the elements in the global numbering, we obtain the system of linear equations presented in equation (11), with the number of unknowns equal to the number of displacements to be determined:

$$
[K]\{w\}=\{f\}
$$

where:

$[\mathrm{K}]$ - Matrix that accumulates the contributions of the $a_{i}$ coefficients, positioned in the global reference;

$\{W\}$ - nodal displacements to be determined;

$\{f\}=\frac{q}{D} \Delta x^{4}$

The system presented in equation (14) has as a solution the displacements of all analysed nodal points. Once the displacements are obtained, the requesting stresses can be found, substituting in the differential equations that correlate the stresses and the displacements (Figure 4). In this way, the stresses are obtained in a plate element.

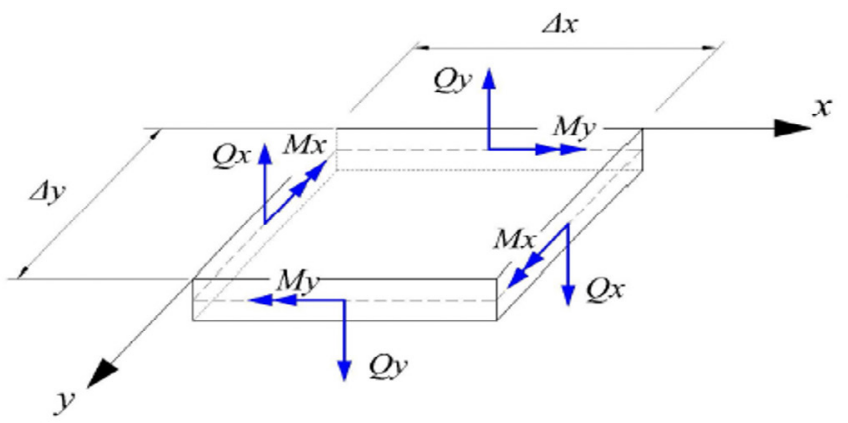

Figure 4. Bending moments and shear forces on a plate element. Source [10].

\section{Calculation of thin slabs}

A routine for the determination of efforts in plates was computationally implemented. Version 2.7 of the Python programming language was used, which can be considered a high-level programming language, interpreted and oriented to objects that presents a dynamic and strong functionality [11].

Based on the input data (which consists of the plate geometry, material property, loading and boundary conditions), the programming starts to promote the generation of the mesh to be used in the determination of nodal displacements considering the points of intersection between lines that were configured for $0.20 \mathrm{~m}$ spacing. It is im-portant to highlight that the characteristics of the steel bars were not modelled in the algorithm, considering that only a simplified analysis was performed, that is, the influence of the reinforcement was not verified through the equivalent elasticity module.

For the application of the finite difference method, the generated mesh was expanded in two points to the outer sides of the slab support limits and the Lagrange equation was applied to each mesh node. The boundary conditions varied between simple supported, fixed or free edges, semi-fixed edges were not considered in this example. The developed algorithm identifies the boundary condition inserted as input data and for the condition of the simple support type, a unit is added to the pivot (central element coefficient, for example, the coefficient in Figure 3), for the fixed support one unit is subtracted from the pivot and when the informed side is free board, the values of the Lagrange equation are modified at the edge and at the internal border.

After this procedure, the weight matrix is assembled and the program calculates the displacement at each point using the finite difference method. The displacement calculation is followed by the plotting of the values found in the form of iso-bands. The bending moment and shear forces are determined from the displacements and for each of these steps, the diagrams representative of the isovalues found are also plotted.

\subsection{Input data}

The input data consists of the boundary conditions, characterized by the interaction between the plate and its support (simple supported, fixed or free edges), the load distributed by area, the spacing of the mesh to be discretized, the geometric characteristics of the slab, such as its dimensions (length, width and thickness), and the properties of the concrete (fck, modulus of elasticity, and Poisson's ratio). Table 1 summarizes the information characterized as input data, the units considered, and the values used in the study of each case developed. 
Table 1. Input data.

\begin{tabular}{lll}
\hline Data & Unit & Value \\
\hline $\mathrm{q}$ & $\mathrm{N} / \mathrm{m}^{2}$ & $4.00 \mathrm{E} 3$ \\
$\mathrm{E}_{\mathrm{cs}}$ & $\mathrm{N} / \mathrm{m}^{2}$ & $30.67 \mathrm{E} 9$ \\
Poisson's ratio & - & $0.20 \mathrm{E} 0$ \\
$\mathrm{f}_{\text {ck }}$ & $\mathrm{N} / \mathrm{m}^{2}$ & $30.00 \mathrm{E} 6$ \\
Width & $\mathrm{m}$ & $3.00 \mathrm{E} 0$ \\
Length & $\mathrm{m}$ & $5.00 \mathrm{E} 0$ \\
Thickness & $\mathrm{m}$ & $0.10 \mathrm{E} 0$ \\
Mesh spacing & $\mathrm{m}$ & $0.20 \mathrm{E} 0$ \\
\hline
\end{tabular}

\subsection{Output data}

The output data consisted of the nodal displace-ments, bending moment and shear stresses, positive and negative, for the directions $x$ and $y$. The plotting for all points of the slab was performed in a graphical form showing regions of isovalues in scale. The maximum displacement value, positive and negative bending moments of greater intensity, as well as the shear forces, were captured at the end of each processing. Figures 5 and 6 show the results for a plate simply supported on all edges.

\section{Case study}

To test the algorithm implemented in different situations, a case study was set up to evaluate the displacement and effort values determined by the finite difference method. Five slabs of a residential room were modelled with accidental loads equal to $1.5 \mathrm{kN} / \mathrm{m}^{2}$, obtained through table 3 of NBR: 6120 [12].

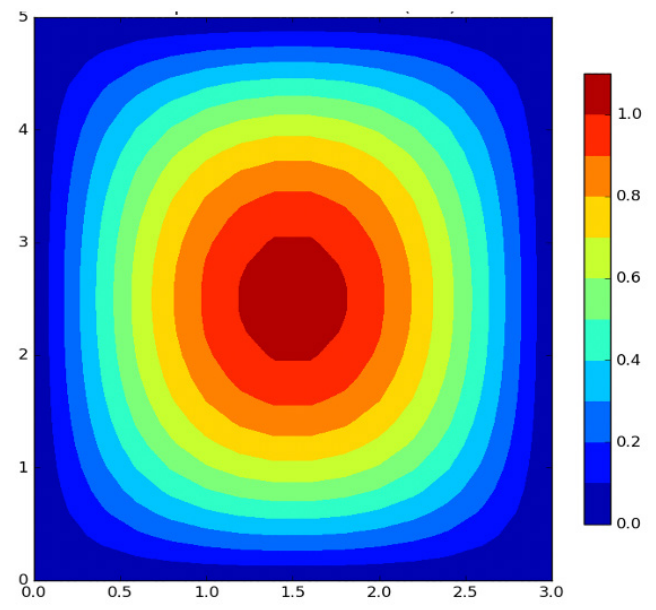

Figure 5. Displacement fields for a fully simply sup-ported slab.

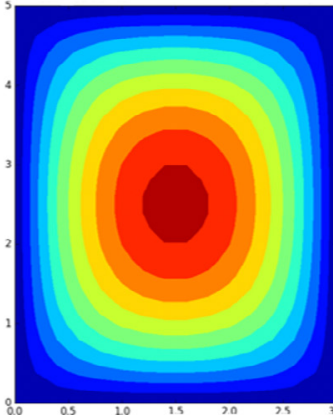

(a)

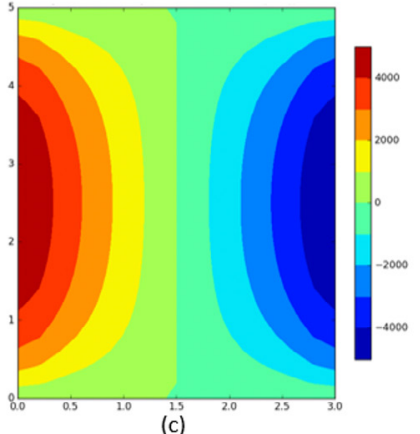

Figure 6. Fields for the fully simply supported slab: (a) bending moment in " $x$ " (Nm/m); (b) bending moment in " $y$ " $(\mathrm{Nm} / \mathrm{m})$; (c) shear forces in " $x$ " (N/m); (d) shear forces in " $y$ " (N/m).

The total load considered was the live load plus the permanent load due to the weight of a $0.10 \mathrm{~m}$ thick reinforced concrete slab (specific weight equal to $25.0 \mathrm{kN} /$ $\mathrm{m}^{3}$ ). All slabs were $3 \mathrm{~m}$ wide according to the " $x$ " axis and $5 \mathrm{~m}$ long according to the " $y$ " axis. The slabs behave like reinforced plates in two directions since the ratio between the longest side and the shortest side was less than two $(\lambda=$ 1.67). Figure 7 shows the five cases of boundary conditions studied, related to the interaction between the plate and its support.

Figure 7(a) shows the four edges simply supported. In Figure 7(b), only the left side of $5.0 \mathrm{~m}$ was fixed and the others remained supported. In Figure 7(c), the two $5.0 \mathrm{~m}$ sides are fixed, and the two $3.0 \mathrm{~m}$ sides are simply supported. The model shown in Figure 7(d), present all edges fixed. Figure 7(e) corresponds to a slab with three sides fixed and a $3.0 \mathrm{~m}$ edge (free) without support. 


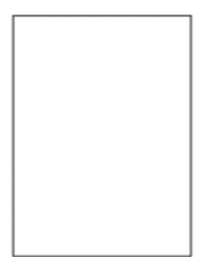

(a)

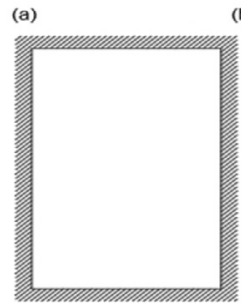

(d)

(b)
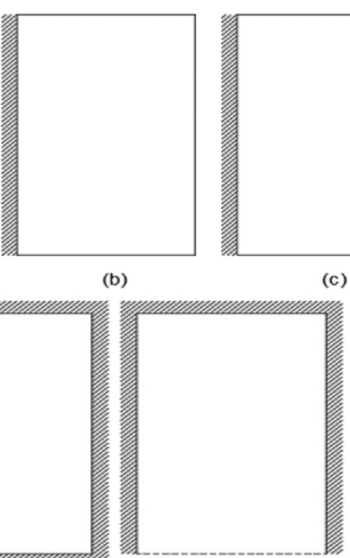

(e)

Figure 7. Cases studied: (a) four simply supported edges; (b) one fixed edge and the others simply supported; (c) two parallel fixed supports and two simple supports; (d) all fixed edges and (e) three fixed edges and one free edge.

\subsection{Verification of results}

The verification of the results presented by the implemented algorithm, both for displacements and for the stresses, was performed by comparing the values from the simulations with the results determined using the coefficients obtained in the design tables that use the theory of elasticity applied to plate elements (Bares's tables). The shear forces obtained by Bares's tables were calculated using the coefficient that indicated the support reactions of the slabs in the beams. Displacements and stresses are shown in table 2 for case "a".

Table 2. Results obtained for case "a".

\begin{tabular}{ccccc}
\hline Data & Unit & $\begin{array}{c}\text { Finite } \\
\text { difference }\end{array}$ & $\begin{array}{c}\text { Bares's } \\
\text { tables }\end{array}$ & $\%$ \\
\hline $\mathrm{F}_{\max }$ & $\mathrm{mm}$ & 1.0485 & 1.04155 & 0.66 \\
$\mathrm{M}_{\mathrm{x}, \max }^{+}$ & $\mathrm{Nm} / \mathrm{m}$ & 3103.63 & 3103.20 & 0.01 \\
$\mathrm{M}_{\mathrm{x}, \max }$ & $\mathrm{Nm} / \mathrm{m}$ & 0.00 & 0.00 & 0.00 \\
$\mathrm{M}^{+} \mathrm{y}, \max$ & $\mathrm{Nm} / \mathrm{m}$ & 1456.93 & 1465.20 & -0.57 \\
$\mathrm{M}_{\mathrm{y}, \max }^{-}$ & $\mathrm{Nm} / \mathrm{m}$ & 0.00 & 0.00 & 0.00 \\
$\mathrm{~V}_{\mathrm{x}, \max }^{+}$ & $\mathrm{N} / \mathrm{m}$ & 4888.34 & 4176 & 14.57 \\
$\mathrm{~V}_{\mathrm{x}, \max }$ & $\mathrm{N} / \mathrm{m}$ & -4888.34 & -4176 & 14.57 \\
$\mathrm{~V}_{\mathrm{y}, \max }^{+}$ & $\mathrm{N} / \mathrm{m}$ & 3998.08 & 3000 & 24.96 \\
$\mathrm{~V}^{-}, \max$ & $\mathrm{N} / \mathrm{m}$ & -3998.08 & -3000 & 24.96 \\
\hline
\end{tabular}
"b".
Table 3. Results obtained for case " $b$ ".

\begin{tabular}{lllll}
\hline Data & Unit & $\begin{array}{l}\text { Finite } \\
\text { difference }\end{array}$ & $\begin{array}{l}\text { Bares's } \\
\text { tables }\end{array}$ & $\%$ \\
\hline $\mathrm{F}_{\max }$ & $\mathrm{mm}$ & 0.5745 & 0.54190 & 5.67 \\
$\mathrm{M}^{+}{ }_{\mathrm{x}, \max }$ & $\mathrm{Nm} / \mathrm{m}$ & 2211.29 & 2185.20 & 1.18 \\
$\mathrm{M}^{-}{ }_{\mathrm{x}, \max }$ & $\mathrm{Nm} / \mathrm{m}$ & -4118.93 & 4201.20 & -2.00 \\
$\mathrm{M}^{+}{ }_{\mathrm{y}, \max }$ & $\mathrm{Nm} / \mathrm{m}$ & 912.87 & 673.20 & 26.25 \\
$\mathrm{M}^{-} \mathrm{y}$ max & $\mathrm{Nm} / \mathrm{m}$ & -823.79 & 0.00 & - \\
$\mathrm{V}^{+}{ }_{x, \max }$ & $\mathrm{N} / \mathrm{m}$ & 6681.16 & 5916 & 11.45 \\
$\mathrm{~V}^{-}, \max$ & $\mathrm{N} / \mathrm{m}$ & -4017.45 & -2196 & 45.34 \\
$\mathrm{~V}^{+}{ }_{y, \max }$ & $\mathrm{N} / \mathrm{m}$ & 4052.51 & 3420 & 15.61 \\
$\mathrm{~V}_{-}^{-}, \max$ & $\mathrm{N} / \mathrm{m}$ & -4052.51 & -3420 & 15.61 \\
\hline
\end{tabular}

Displacements and stresses are shown in table 4 for case "c".

Table 4. Results obtained for case "c".

\begin{tabular}{lllll}
\hline Data & Unit & $\begin{array}{l}\text { Finite } \\
\text { difference }\end{array}$ & $\begin{array}{l}\text { Bares's } \\
\text { tables }\end{array}$ & $\%$ \\
\hline $\mathrm{F}_{\max }$ & $\mathrm{mm}$ & 0.3172 & 0.30317 & 4.43 \\
$\mathrm{M}^{+}{ }_{\mathrm{x}, \max }$ & $\mathrm{Nm} / \mathrm{m}$ & 1466.71 & 1472.40 & -0.39 \\
$\mathrm{M}^{-} \mathrm{x}$ max & $\mathrm{Nm} / \mathrm{m}$ & -2981.96 & -2980.80 & 0.04 \\
$\mathrm{M}^{+}{ }_{\mathrm{y}, \max }$ & $\mathrm{Nm} / \mathrm{m}$ & 632.26 & 442.80 & 29.97 \\
$\mathrm{M}_{\mathrm{y}, \max }$ & $\mathrm{Nm} / \mathrm{m}$ & -596.39 & 0.00 & - \\
$\mathrm{V}_{\mathrm{x}, \max }^{+}$ & $\mathrm{N} / \mathrm{m}$ & 5375.08 & 4956 & 7.80 \\
$\mathrm{~V}^{-}, \max$ & $\mathrm{N} / \mathrm{m}$ & -5375.08 & -4956 & 7.80 \\
$\mathrm{~V}^{+}{ }_{\mathrm{y}, \max }$ & $\mathrm{N} / \mathrm{m}$ & 3305.47 & 1728 & 47.72 \\
$\mathrm{~V}_{\mathrm{y}, \max }$ & $\mathrm{N} / \mathrm{m}$ & -3305.47 & -1728 & 47.72 \\
\hline
\end{tabular}

Table 5 shows the results for case "d".

Table 5. Results obtained for case "d".

\begin{tabular}{lllll}
\hline Data & Unit & $\begin{array}{l}\text { Finite } \\
\text { difference }\end{array}$ & $\begin{array}{l}\text { Bares's } \\
\text { tables }\end{array}$ & $\%$ \\
\hline $\mathrm{F}_{\max }$ & $\mathrm{mm}$ & 0.2932 & 0.28310 & 3.44 \\
$\mathrm{M}^{+}{ }_{\mathrm{x}, \max }$ & $\mathrm{Nm} / \mathrm{m}$ & 1363.21 & 1368.00 & -0.35 \\
$\mathrm{M}^{-} \mathrm{x}$ max & $\mathrm{Nm} / \mathrm{m}$ & -2823.50 & -2836.80 & -0.47 \\
$\mathrm{M}^{+}{ }_{\mathrm{y}, \max }$ & $\mathrm{Nm} / \mathrm{m}$ & 566.60 & 529.20 & 6.60 \\
$\mathrm{M}_{\mathrm{y}, \max }$ & $\mathrm{Nm} / \mathrm{m}$ & -2002.39 & -2059.20 & -2.84 \\
$\mathrm{~V}^{+} \mathrm{x}$ max & $\mathrm{N} / \mathrm{m}$ & 5267.37 & 4176 & 20.72 \\
$\mathrm{~V}_{\mathrm{x}, \max }$ & $\mathrm{N} / \mathrm{m}$ & -5267.37 & -4176 & 20.72 \\
$\mathrm{~V}^{+}{ }_{\mathrm{y}, \max }$ & $\mathrm{N} / \mathrm{m}$ & 4263.92 & 3000 & 29.64 \\
$\mathrm{~V}^{-}{ }_{\mathrm{y}, \max }$ & $\mathrm{N} / \mathrm{m}$ & -4263.92 & -3000 & 29.64 \\
\hline
\end{tabular}

Table 6 shows the results for case "e". 
Table 6. Results obtained for case "e".

\begin{tabular}{lllll}
\hline Data & Unit & $\begin{array}{l}\text { Finite } \\
\text { difference }\end{array}$ & $\begin{array}{l}\text { Bares's } \\
\text { tables }\end{array}$ & $\%$ \\
\hline $\mathrm{F}_{\max }$ & $\mathrm{mm}$ & 0.3488 & 0.35387 & -1.45 \\
$\mathrm{M}^{+}{ }_{\mathrm{x}, \max }$ & $\mathrm{Nm} / \mathrm{m}$ & 1623.89 & 1616.40 & 0.46 \\
$\mathrm{M}^{-}{ }_{\mathrm{x} \text { max }}$ & $\mathrm{Nm} / \mathrm{m}$ & -3117.07 & -3045.60 & 2.29 \\
$\mathrm{M}^{+}{ }_{\mathrm{y}, \max }$ & $\mathrm{Nm} / \mathrm{m}$ & 532.11 & 356.40 & 33.02 \\
$\mathrm{M}^{-}$,max & $\mathrm{Nm} / \mathrm{m}$ & -1994.39 & -2005.20 & -0.54 \\
$\mathrm{~V}^{+}{ }_{\mathrm{x}, \max }$ & $\mathrm{N} / \mathrm{m}$ & 5563.88 & - & - \\
$\mathrm{V}_{\mathrm{x}, \max }^{+}$ & $\mathrm{N} / \mathrm{m}$ & -5563.88 & - & - \\
$\mathrm{V}^{+}{ }_{\mathrm{y} \text { max }}$ & $\mathrm{N} / \mathrm{m}$ & 2067.36 & - & - \\
$\mathrm{V}_{\mathrm{y}, \max }$ & $\mathrm{N} / \mathrm{m}$ & -4245.13 & - & - \\
\hline
\end{tabular}

The data of the shear stresses could not be determined for the "e" case (three fixed supports and a free edge) because the Bares's tables used do not provide the support reactions for this situ-ation.

\subsection{Analysis and discussions}

In most cases, the percentage differences between stresses determined by the finite difference method were small. It was possible to perceive coherence as to the position of the highest values considering the oriented axes. Comparing the arrows determined by the two methods, it was found that there were no percentage differences greater than $5.6 \%$, as can be seen in the tables. An arrow of $0.57 \mathrm{~mm}$ was obtained by the finite difference method and $0.54 \mathrm{~mm}$ using the Bares's tables (case "b"). For the positive and negative bending moments in the " $x$ " and " $y$ " directions, the percentage differences were not greater than $6.6 \%$, except for the positive moments in cases "b", "c" and "e" that presented percentage values of up to $33.02 \%$. It is also observed, that the finite difference method presented values of negative bending moments on the supported sides (direction " $y$ ") of cases "b" (823.79 $\mathrm{Nm} / \mathrm{m})$ and "c" (-596, 39 Nm/m), while such stresses are not considered in the Bares's tables.

Figure 8(a) shows the graphs of positive and negative bending moments isovalues for the " $y$ " direction of case " $\mathrm{b}$ ". It is observed by the isovalue bands indicated in the graph that in the region of the connection corner between the fixed and the simple support a negative moment develops due to the influence that the fixed support has on the beginning of the simply supported section. Such behavior could also be seen in the isovalue graph for case "c", shown in Figure 8(b).

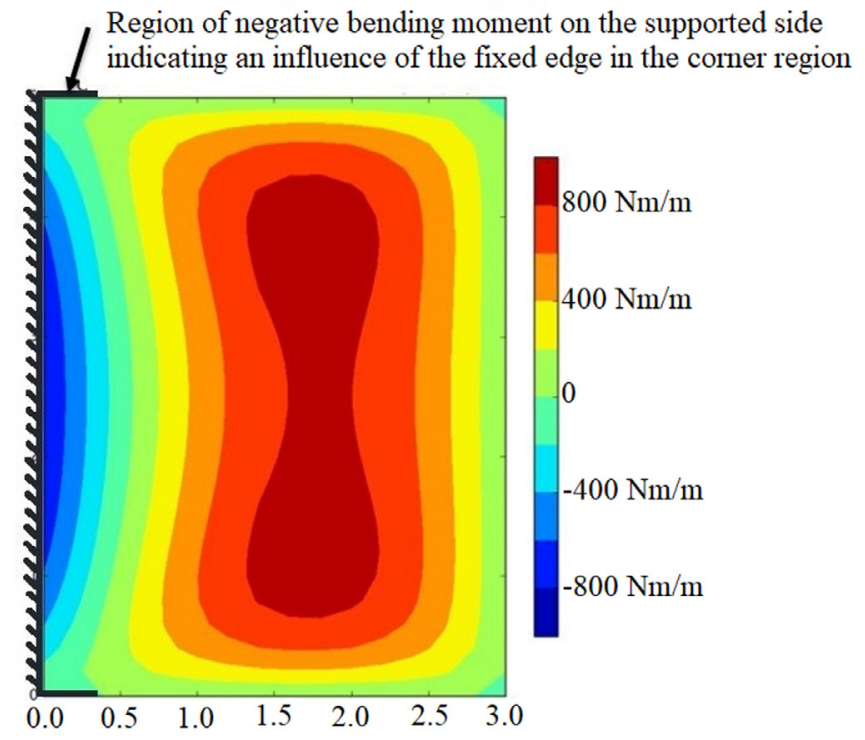

(a)

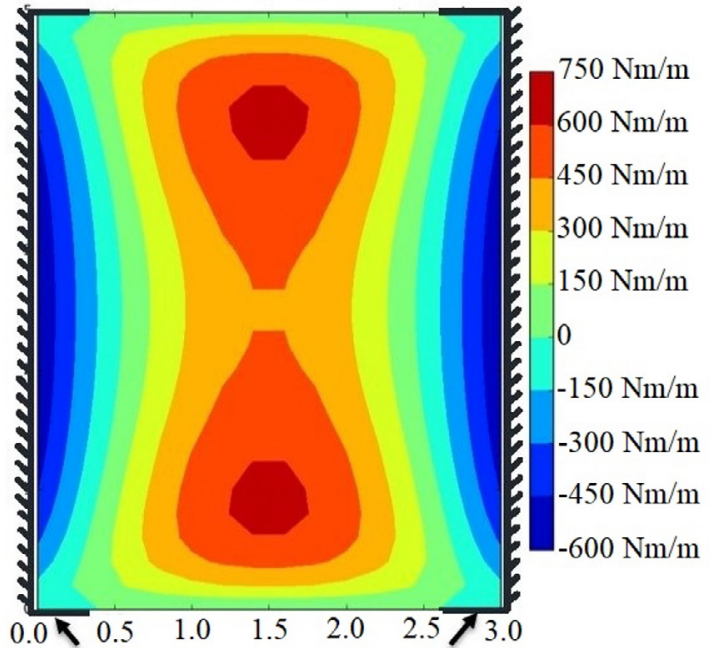

Region of negative bending moment on the supported side indicating an influence of the fixed edge in the corner region

(b)

Figure 8. Isovalues of positive and negative bending moments for direction " $y$ " (a) for case " $b$ " and (b) for case "c". (Horizontal axes in meters)

The shear efforts were the output data of the processing that showed the biggest percentage differences. It should be noted that the shear forces on the slab that had a free edge were not evaluated. Despite the divergence of the values deter-mined by the two methods, it was possible to perceive symmetry when the opposite edges present the same boundary conditions.

Figure 9 shows the results of shear stresses in the " $y$ " direction for the "c" case (two opposite sides fixed). Despite corresponding to the greatest differences between the stresses deter-mined according to the two methods $(47.72 \%)$, it is 
possible to observe the expected symmetry between the values from the existing support conditions.

As the Bares's tables show an average value between the different stresses along the beam length and the results obtained by the finite difference method were the highest values observed, the marked difference is attributed to the simplifications that guided the making of the tables for dimensioning of reinforced concrete slabs.

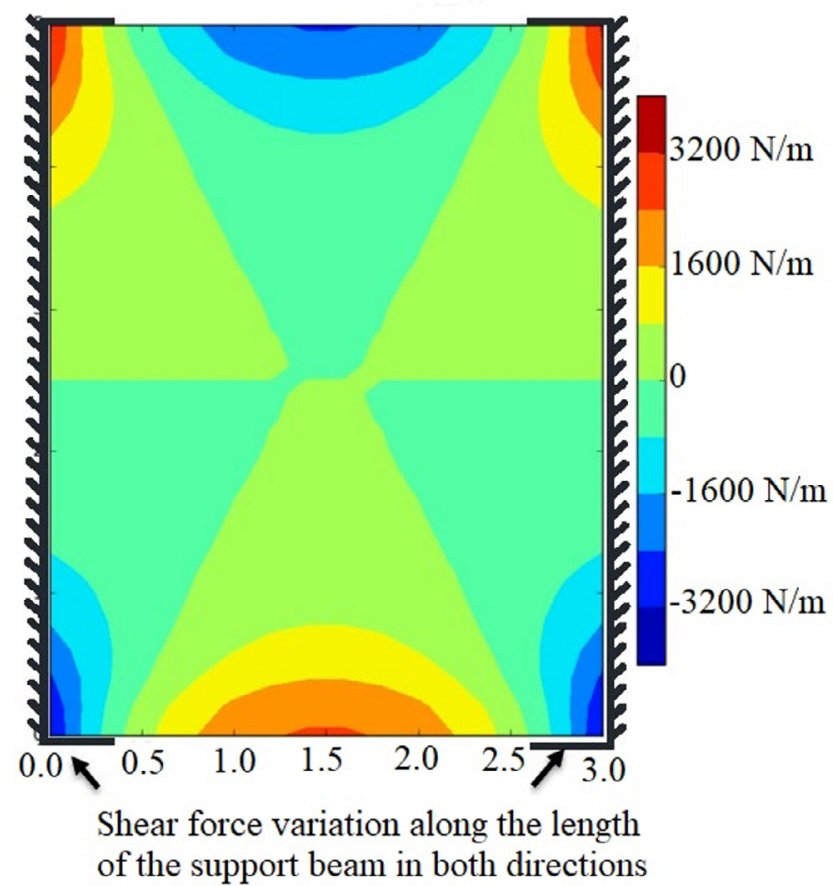

Figure 9. Isovalues of shear forces in the "y" direction for the case "c". (Horizontal axes in meters)

\section{Conclusions}

Through this research, it was found that the finite difference method is a good alternative for the resolution of thin plates, as the results were similar to the classic solutions proposed in the literature.

The simplification adopted in the tables (which use the theory of elasticity applied to the plates) in which an average value is considered over the entire length of the support. In some cases, it can generate a detail of inadequate reinforcement positioning, mainly when considering the distribution of stresses in the corner regions (support region). Using the finite difference method, it is possible to visualize a more real distribution of these stresses, thus leading to a better reinforcement arrangement and eventual savings in the structural design.

Thus, it was found that depending on the boundary conditions, some results have a better refinement through the method of finite differ-ences compared to the process of classical literature (Bares's tables), which can be a mathematical tool that can be used by software due to its ease of implementation.

\section{Acknowledgments}

The authors would like to thank the National Council for Scientific and Technological Development (CNPq) for their scientific support.

\section{References}

[1] R. Bares. Tablas para el cálculo de placas y vigas parede. Barcelona: Editora Gustavo Gili S/A, 1972.

[2] R. C. Carvalho and J. R. F. Filho. Cálculo e detalhamento de estruturas usuais de concreto armado. 3th ed. São Carlos: Editora UFSCar, 2012.

[3] J. N. Reddy. Theory and analysis of elastic plates and shells. CRC Press, Taylor and Francis, 2007.

[4] Associação Brasileira de Normas Técnicas ABNT: NBR 6118 "Projeto de estruturas de concreto - Procedimento". Rio de Janeiro, 2014.

[5] J. D. Hoffman and S. Frankel. Numerical methods for engineers and scientists. CRC Press, Boca Raton, 2001.

[6] G. D. Smith. Numerical solution of partial differential equations: finite difference methods. 3rd ed. Oxford University Press, 1985.

[7] J. Biezuner. Class notes. (2016, November 24) [Online]. Available: http://www.mat.ufm g.br/ rodney/notas de aula/df.pdf.

[8] J. M. Araújo. Curso de concreto armado. 4th ed. v. 2. Rio Grande, Dunas, 2014.

[9] D. A. O. Martinelli, I. Montanari and W. Savassi. "Placas Elásticas". EESC-USP, São Carlos, Brazil, Publicação 018/93, 1986.

[10] S. D. C. Júnior. "Elaboração de um programa computacional para o cálculo e dimensionamento de lajes maciças". Final year project, Faculdade de Engenharia, Universidade Federal de Juiz de Fora, Juiz de Fora, 2008.

[11] J. V. Guttag. Introduction to Computation and Programming Using Python: With Application to Understanding Data. 2nd ed. Cambridge, MIT Press, 2016.

[12] Associação Brasileira de Normas Técnicas ABNT: NBR 6120 "Cargas para o cálculo de estruturas de edificações”. Rio de Janei-ro, 1980. 